\title{
Depression and/or Potentiation of Cortical Responses after Status Epilepticus in Immature Rats
}

\author{
G. TSENOV, P. MAREŠ \\ Department of Developmental Epileptology, Institute of Physiology, Academy of Sciences of the \\ Czech Republic, Prague, Czech Republic
}

Received June 20, 2006

Accepted July 17, 2006

On-line available August 22, 2006

\begin{abstract}
Summary
Lithium-pilocarpine status epilepticus (SE) resulted in delayed changes of single cortical interhemisperic (transcallosal) responses in immature rats. Low-frequency stimulation inducing depression and/or potentiation was studied to analyze possible dynamic changes in cortical responses. Status was elicited in 12-day-old (SE12) or 25-day-old (SE25) rats. Control siblings received saline instead of pilocarpine. Interhemispheric responses were elicited by stimulation of the sensorimotor region of the cerebral cortex $3,6,9,13$, or 26 days after status. A series of 5 biphasic pulses with intensity equal to twofold threshold were used for stimulation. The interval between pulses was 100, 125, 160, 200 or $300 \mathrm{~ms}$, eight responses were always averaged. Peak amplitude of the first positive, first negative and second positive waves was measured and responses to the second, third, fourth and fifth pulse were compared with the first one. Animals after status epilepticus as well as lithium-paraldehyde controls exhibit a frequency depression at nearly all the intervals studied. An outlined increase of responses in SE rats in comparison with the controls three days after SE stayed just below the level of statistical significance. In addition, animals in the SE12 group exhibited potentiation of responses at this interval after SE. With longer intervals after SE, the relation between SE and control animals changed twice resulting in a tendency to lower amplitude of responses in SE than in control rats 26 days after SE. Rats in the SE25 group exhibited higher responses than controls 13 days after status, but this difference was not present at the longest interval after SE. Low-frequency stimulation did not reveal increased cortical excitability as a long-lasting consequence of status epilepticus induced in immature rats. In addition, the outlined differences between SE and control rats changed with the time after SE.
\end{abstract}

\section{Key words}

Status epilepticus $\bullet$ Ontogeny $\bullet$ Evoked potentials $\bullet$ Frequency depression $\bullet$ Rats

\section{Introduction}

Convulsive status epilepticus (SE) results in brain excitotoxic damage in adult experimental animals (Olney et al. 1986). There is a long-lasting discussion about morphological consequences of SE in the immature brain. The very first experimental data using kainic acidinduced SE failed to find neuronal damage in the hippocampus (CA3 field) if SE was induced in rat pups younger than 18 days (Sperber et al. 1991, Holmes 1997). These negative findings led to the conclusion that the immature brain is resistant to morphological damage after 
SE. In contrast, serious damage was found even after SE induced by kainic acid in 7-day-old rat pups (Babb et al. 1995, Leite et al. 1996). The damage could be demonstrated only after a long interval (up to several months) and its distribution was different from that described in adult animals. Data from high dose pilocarpine- and lithium-pilocarpine models of SE confirmed the vulnerability of the immature brain. Degenerating neurons were found not only in the hippocampal formation but also in other brain structures (Sankar et al. 1998, 2000, Kubová et al. 2001). Similarly, brain damage with a somewhat different time course was described after SE induced by electrical stimulation of entorhinal cortex. Sankar et al. (2000) therefore concluded that the consequences of SE are age- as well as model-dependent. As far as the localization of degenerating neurons is concerned, Turski et al. (1983) mentioned more damaged structures (e.g. temporal cortex, thalamus) in their original description of the pilocarpine model of SE. Our laboratory recently described in detail neuronal degeneration in the thalamus (Kubová et al. 2001, 2002, 2004, Druga et al. 2005). Consequently, seizures in the immature brain must no longer be taken as ,innocent“" (Holmes and Ben-Ari 1998).

There are almost no data available about possible morphological damage of neocortex after SE in immature animals, in spite of the fact that neocortex plays an important role in epileptic seizures in infancy and early childhood (Aicardi 1998). Cavalheiro et al. (1987) mentioned that neocortex exhibited neuronal cell loss in 5 out of 14 rats with pilocarpine SE at the age of 11-21 days. In addition, Sankar et al. (1997) demonstrated the presence of irreversibly damaged neurons in the cortex after lithium-pilocarpine SE in rat pups 3 and 4 weeks old. This paucity of data is surprising because it was shown that epileptiform EEG activity in kainate-induced status epilepticus (Cavalheiro et al. 1983, Cherubini et al. 1983), as well as in seizures induced by hypoxia in 10-day-old rats (Jensen et al. 1998) started in the cortex; hippocampus is involved with some delay. Hyperexcitability as a functional consequence of seizures elicited at an early postnatal age was described in the hippocampus; it was demonstrated after hypoxia-induced seizures (Jensen et al. 1992, 1998), tetanus toxin-induced seizures (Lee et al. 1995) and hyperthermic seizures (Chen et al. 1999, Dube et al. 2000). These findings led us to the study of cortical excitability after status epilepticus elicited at two different developmental stages (12- and 25-day-old rat pups). We found opposite changes in interhemispheric (transcallosal) responses in the sensorimotor cortex of rats exposed to SE at the age of 12 and 25 days. Both groups demonstrated changes only after two and more weeks after SE; amplitude of responses was lower in SE12 rats than in controls, whereas the input-output curve was steeper in SE25 animals than in control siblings (Mareš et al. 2005). We hence decided to continue our study with low-frequency stimulation to use frequency potentiation and/or depression as a tool to study the dynamics of cortical responses. Basic developmental data on transcallosal responses and their potentiation have been reported (Seggie and Berry 1972, Mareš et al. 1993a,b).

\section{Methods}

The experimental protocol was approved by Animal Care and Use Committee of the Institute of Physiology to be in agreement with Animal Protection Law of the Czech Republic (which is fully compatible with European Community Council Directives 86/609/EEC). Male albino rats of the Wistar strain (breeding colony of the Institute of Physiology, Academy of Sciences of the Czech Republic) were used in these experiments. The day of birth was denoted as day 0 . The animals were kept under standard conditions (temperature $22 \pm 1{ }^{\circ} \mathrm{C}$, humidity 50-60\%, 12/12 light regime). Animals had free access to food and water ad libitum.

Status epilepticus was induced by pilocarpine (40 mg/kg i.p.) in 12- and 25-day-old rats (Rejchrtová et al. 2005). All animals received $\mathrm{LiCl}$ (3 meq/kg i.p.) $24 \mathrm{~h}$ earlier. Only rats exhibiting clear-cut convulsive status epilepticus characterized by clonic seizures of the head and forelimb muscles were included into the present study. Paraldehyde ( $0.3 \mathrm{ml} / \mathrm{kg}$ i.p. $)$ was administered after two hours of continuous motor seizures to interrupt seizures and to decrease mortality. Twelve-day-old animals were returned to their mothers, older rats needed intensive care (hydration, feeding with soft paste) for at least two days. Siblings treated in the same way with pilocarpine replaced by saline were used as control (lithium-paraldehyde) group; they were returned to their mothers at the same time as SE animals.

Experiments were performed 3, 6, 9, 13, and 26 days after SE; each age group consisted of 7-11 rats. Surgical preparation was performed under ether anesthesia. Stimulation electrodes were implanted epidurally on the right hemisphere at coordinates $\mathrm{AP}=$ 


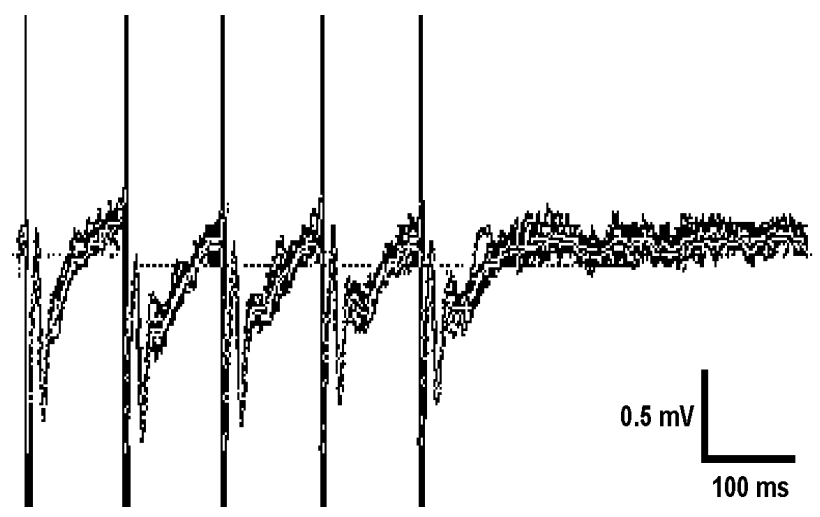

Fig. 1. Superimposed and averaged (light curve) responses to a series of 5 stimuli with a 125 -ms interval from a 18-day-old-rat ( 6 days after status at the age of 12 days). An upward deflection means positivity of cortical electrode. Time mark $100 \mathrm{ms,}$ amplitude calibration $0.5 \mathrm{mV}$.

+1 and $-1, \mathrm{~L}=2 \mathrm{~mm}$ in relation to the bregma, i.e. sensorimotor region was in the center of stimulated area, the recording electrode was put over left sensorimotor cortex at $\mathrm{AP}=0, \mathrm{~L}=2 \mathrm{~mm}$. The reference electrode was in the nasal bone, ground electrode in the occipital bone. Surgery lasted less than $15 \mathrm{~min}$, then the animals were allowed to recover for at least one hour. Rat pups with immature thermoregulation (up to postnatal day 18) were kept on a pad electrically heated to $34^{\circ} \mathrm{C}$ (i. e. the temperature in the nest). Stimulation was performed by biphasic pulses from a constant-current stimulator; first threshold intensity was established and then series of 5 pulses with twofold threshold intensity were applied throughout the experiment. Five different intervals between individual stimuli in the series were used -100 , 125, 160, 200 and $300 \mathrm{~ms}$.

Activity was digitalized at a rate of $1 \mathrm{kHz}$ and saved on a hard disc. Eight responses were always averaged by a PC-based system (Kaminskij Biomedical Research Systems, Prague, digitalization rate $1 \mathrm{kHz}$ ) (Fig.1). The differences of amplitude between peaks of the first positive (P1) and the first negative (N1) as well as between N1 and the second positive (P2) waves were measured and amplitudes of the second, third, fourth and fifth responses were related to the first. The oldest age group (26 days after SE elicited at the age of 25 days) exhibited P1 wave with a very short latency so that measurement of the amplitude of P1 was not fully reliable because of interference with the stimulation artifact, therefore only data for N1P2 amplitude are presented in this age group.

Data were statistically evaluated by means of the Mann-Whitney test (SigmaStat ${ }^{\circledR}$, Systat Software Inc.) 125-ms interval
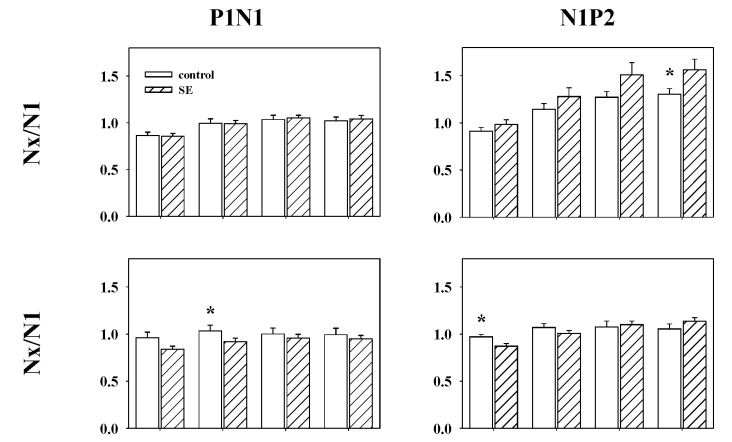

$12+3$
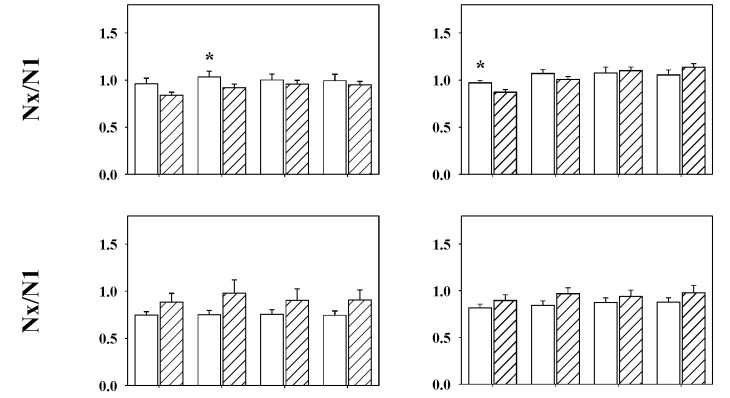

$12+6$
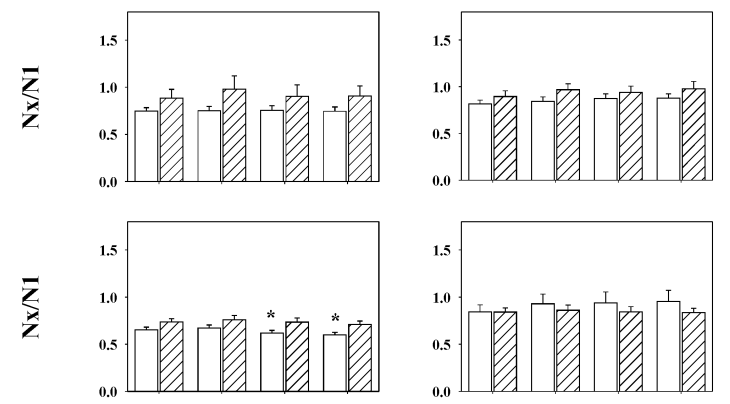

$12+9$
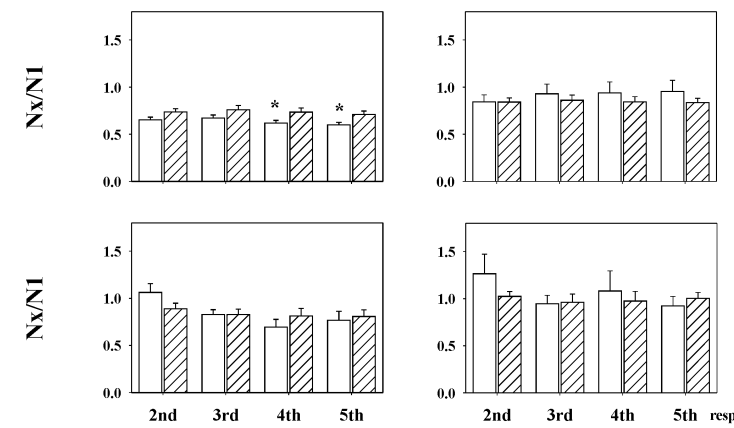

$12+13$

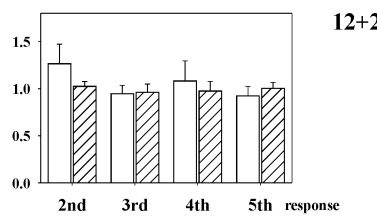

Fig. 2. Relative amplitude of the P1N1 (left) and N1P2 (right) waves in the second, third, fourth and fifth (abscissae from left to right) responses elicited with interstimuli intervals of $125 \mathrm{~ms}$ in the animals undergoing status at the age of 12 days (obliquely hatched columns) and their lithium-paraldehyde controls (white columns). From top to bottom: 3, 6, 9, 13 and 26 days after status. Ordinates: 1.0 means amplitude equal to that of the first response. Mean \pm S.E.M. is always presented, asterisks denote significant difference between status and control groups.

because of predominant non-Gaussian distribution; $\mathrm{p}<0.05$ was taken as significant.

\section{Results}

Generally, a tendency to differences between SE and control groups was often present, but only a few of these differences reached the level of significance (Figs 2-4). Comparison of many data yielded values of $p$ between 0.05 and 0.1 ; these data are described as tendencies.

\section{P12 group (Fig. 2)}

Frequency depression was more common in all interval groups. Clear-cut frequency potentiation (amplitude of responses higher than $130 \%$ of the first evoked potential) was recorded only in the $12+3$ groups if 
125-ms interval
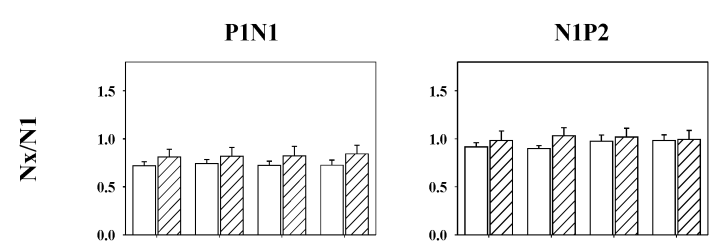

$25+3$
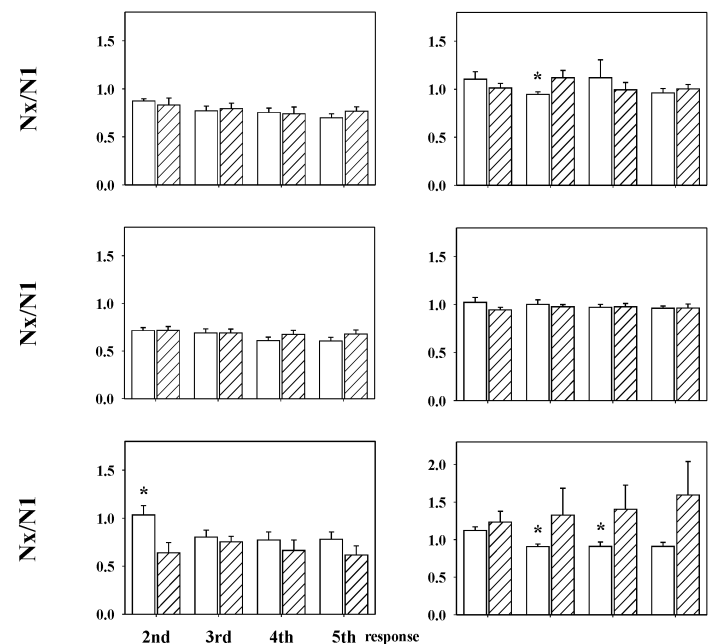

$25+13$
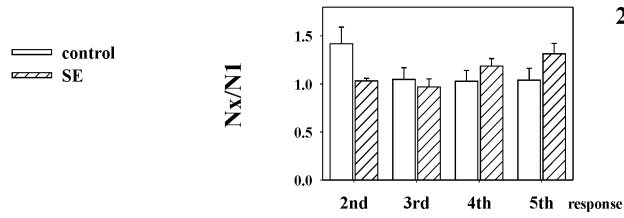

Fig. 3. Relative amplitude of the second, third, fourth and fifth responses elicited with interstimuli intervals of $125 \mathrm{~ms}$ in the animals undergoing status at the age of 25 days and appropriate controls. Details as in Fig. 2, only data for P1N1 amplitude in the oldest group are missing because of interference of stimulus artifact with P1 wave.

short interstimuli intervals were used and the N1P2 amplitude was measured. This potentiation was more marked in the SE group. Three days later the SE group exhibited lower responses than the controls (the level of significance was reached with $125-\mathrm{ms}$ and $160-\mathrm{ms}$ intervals). On the contrary, responses in $12+9$ and $12+13$ days old rats in the SE group exhibited a tendency to have a higher amplitude than responses in the control group especially as the P1N1 difference was concerned. This situation was again changed in the oldest group (12+26 days), where a tendency to lower amplitude in the SE group than in control rats prevailed.

\section{P25 group (Figs 3 and 4)}

Frequency depression was common in this group whereas only at an interval of 13 days frequency potentiation of the N1P2 waves was observed. Potentiation of the second response was exceptionally observed with longer intervals between stimuli. 200-ms interval
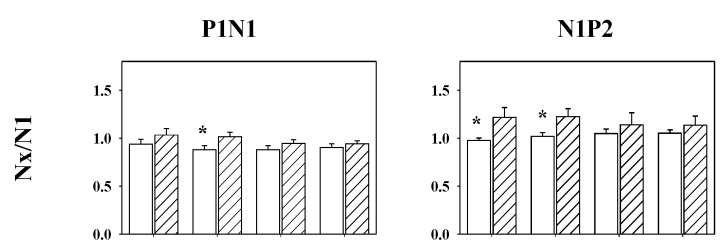

$25+3$
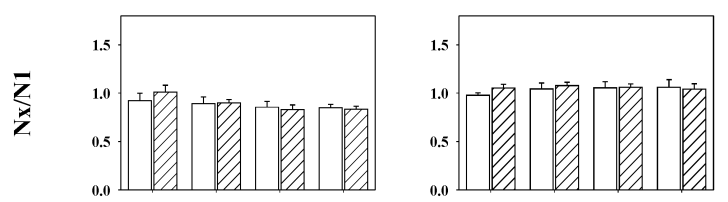

$25+6$
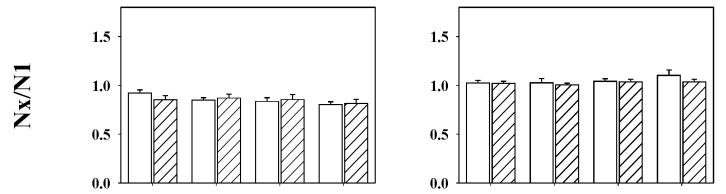

$25+9$

$\bar{z}$
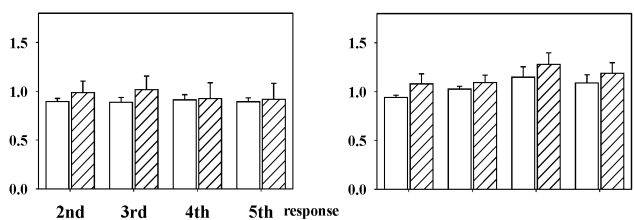

$25+13$

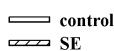

$\bar{z}$

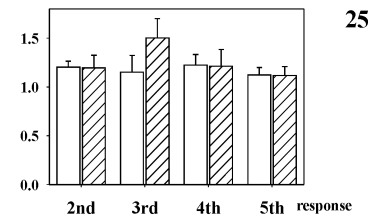

$25+26$

Fig. 4. Relative amplitude of the second, third, fourth and fifth responses elicited with interstimuli intervals of $200 \mathrm{~ms}$ in the animals undergoing status at the age of 25 days. Details as in Figs. 2 and 3.

At the shortest interval after SE $(25+3$ days $)$ responses tended to be higher in SE than in control rats, especially at 200- and 300-ms intervals. Six as well as 9 days after SE responses did not exhibit consistent changes. Higher amplitude of evoked potentials in SE than in the control group was observed 13 days after intervention especially as N1P2 amplitude at shorter interstimuli intervals was concerned. Again, no consistent changes in the amplitude of responses were found at the longest interval, i.e. at the age of 51 days.

\section{Discussion}

No clear signs of potentiation were found in rats undergoing status epilepticus at either age. On the contrary, frequency depression was common. In addition, significant differences between $\mathrm{SE}$ and lithiumparaldehyde control animals were rather an exception. If the tendencies are taken into account, results at different 
intervals after SE exhibited phasic changes. A surprising but consistent finding was a tendency of rats undergoing SE to have a higher amplitude of responses than their control siblings at the shortest interval studied (3 days). The level of significance was reached more often if N1P2 waves were measured. This is contrary to our previous findings where we found responses to single stimuli in animals exposed to status at the age of 25 days which did not exhibit a higher amplitude of P1N1 waves and steeper input-output curve 3 days after SE but at longer intervals (Mareš et al. 2005). Under normal conditions, frequency potentiation of the P1N1 waves appears since the fourth postnatal week (Mareš et al. 1993b). Failure to record frequency potentiation of interhemispheric responses in both SE and control animals older than three weeks might be associated with separation of animals from their mothers; intensity of the stimulation current may also play a role. The constant-current stimulator and averaging technique probably resulted in lower threshold intensities than in our older series of experiments performed with a constant-voltage stimulator (Mareš et al. 1993b). Intervals between stimuli can be excluded as the cause for our findings - the whole range of intervals (from 100 to $300 \mathrm{~ms}$ ) yielded the same results in 25-day-old and adult rats in the original developmental study (Mareš et al. 1993b). There were some differences between responses if P1N1 and N1P2 amplitudes were compared. The N1P2 amplitude seems to be more often altered than P1N1. It could be due to different generators of individual waves: P1 and N1 represent monosynaptic excitation of deep and superficial cortical layers, whereas the P2 wave represents a polysynaptic part of the interhemispheric evoked potential (Grafstein 1959).

There is degeneration of at least some cortical neurons as demonstrated in adult rats by Turski et al. (1983) and in rats pups by Cavalheiro et al. (1987) as well as in our previous paper (Mareš et al. 2005). We found more degenerating neurons (mostly cells with characteristics of interneurons) $24 \mathrm{~h}$ after status in the 25day-old group than in the 12-day-old group (Mareš et al. 2005). Degenerating neurons exhibit features of interneurons (never of pyramidal cells) so that the basic cortical dipole generating P1 and N1 waves is probably not markedly changed by status epilepticus. Unfortunately, there are no data on cortical functions after status epilepticus in immature rats in the literature to have a possibility of comparison. Potentiation of the second response in some tests has to be studied in separate experiments focused on possible paired-pulse potentiation and its maturation (Mareš et al. 1993b). Late components of responses could be better analyzed in a paired-pulse paradigm. Easier elicitation of epileptic seizures (i.e. higher excitability) found in limbic structures after various epileptic insults in immature rats (Jensen et al., 1992, 1998, Lee et al. 1995, Chen et al. 1999, Dube et al. 2000, Jensen and Baram 2000) remains to be tested in the cerebral cortex. Our first results with epileptic afterdischarges induced by electrical stimulation of the sensorimotor cortical area speak in favor of a substantial difference between neocortex and limbic structures (Tsenov et al. - in preparation).

We demonstrated changes of the ratio of responses between SE and control rats at different intervals after status. This finding is in full agreement with our former study of motor performance of rat pups after SE (Kubová et al. 2000). This could be taken as the main result of our present study and a warning to avoid general conclusions based on the results of only one interval after status epilepticus.

\section{Acknowledgements}

This study was supported by a grant No. 309/03/0770 of the Grant Agency of the Czech Republic and by a research project AVOZ 50110509.

\section{References}

AICARDI J: Syndromes of infancy and early childhood. In: Epilepsy: A Comprehensive Textbook. ENGEL J, PEDLEY TA (eds), Lippincott-Raven, Philadelphia, 1998, pp 2263-2265.

BABB TL, LEITE JP, MATHERN GW, PRETORIUS JK: Kainic acid induced hippocampal seizures in rats: comparison of acute and chronic seizures using intrahippocampal versus systemic injection. Ital J Neurol Sci 16: 139-144, 1995.

CAVALHEIRO EA, DE FEO MR, MECARELLI O, RICCI GF: Intracortical and intrahippocampal injections of kainic acid in developing rats. An electrographic study. Electroenceph Clin Neurophysiol 56: 480-486, 1983.

CAVALHEIRO EA, SILVA DF, TURSKI WA, CALDERAZZO-FILHO LS, BORTOLOTTO ZA, TURSKI L: The succeptibility of rats to pilocarpine-induced seizures is age-dependent. Dev Brain Res 37: 43-58, 1987. 
CHEN K, BARAM TZ, SOLTESZ I: Febrile seizures in the developing brain result in persistent modification of neuronal excitability in limbic circuits. Nat Med 5: 888-894, 1999.

CHERUBINI E, DE FEO MR, MECARELLI O, RICCI GF: Behavioral and electrographic patterns induced by systemic administration of kainic acid in developing rats. Dev Brain Res 9: 69-77, 1983.

DRUGA R, KUBOVÁ H, MAREŠ P: Degenerative neuronal changes in the rat thalamus induced by status epilepticus at different developmental stages. Epilepsy Res 63: 43-65, 2005.

DUBE C, CHEN K, EGHBAL-AHMADI M, BRUNSON K, SOLTESZ I, BARAM TZ: Prolonged febrile seizures in the immature rat model enhance hippocampal excitability long term. Ann Neurol 47: 336-344, 2000.

GRAFSTEIN B: Organization of callosal connections in suprasylvian gyrus of cat. J Neurophysiol 22: 504-515, 1959.

HOLMES GL: Epilepsy in the developing brain: lessons from the laboratory and clinic. Epilepsia 38: 12-30, 1997.

HOLMES GL, BEN-ARI Y: Seizures in the developing brain: perhaps not so benign after all. Neuron 21: 1231-1234, 1998.

JENSEN FE, BARAM TZ: Developmental seizures induced by common early-life insults: short- and long-term effects on seizure susceptibility. Mental Retard Dev Disab Res Rev 6: 253-257, 2000.

JENSEN FE, HOLMES GL, LOMBROSO CT, BLUME HK, FIRKUSNY IR: Age-dependent changes in long-term seizure susceptibility and behavior after hypoxia in rats. Epilepsia 33: 971-980, 1992.

JENSEN FE, WANG C, STAFSTROM CE, LIU Z, GEARY C, STEVENS MC: Acute and chronic increases in excitability in rat hippocampal slices after perinatal hypoxia in vivo. J Neurophysiol 79: 73-81, 1998.

KUBOVÁ H, HAUGVICOVÁ R, SUCHOMELOVÁ L, MAREŠ P: Does status epilepticus influence the motor development of immature rats? Epilepsia 41(Suppl 6): 64-69, 2000.

KUBOVÁ H, DRUGA R, LUKASIUK K, SUCHOMELOVÁ L, HAUGVICOVÁ R, JIRMANOVÁ I, PITKÄNEN A: Status epilepticus causes necrotic damage in the mediodorsal nucleus of the thalamus in immature rats. J Neurosci 21: 3593-3599, 2001.

KUBOVÁ H, DRUGA R, HAUGVICOVÁ R, SUCHOMELOVÁ L, PITKÄNEN A: Dynamic changes of status epilepticus-induced neuronal degeneration in the mediodorsal nucleus of the thalamus during postnatal development of the rat. Epilepsia 43 (Suppl 5): 54-60, 2002.

KUBOVÁ H, MAREŠ P, SUCHOMELOVÁ L, BROŽEK G, DRUGA R, PITKÄNEN A: Status epilepticus in immature rats causes neuronal death, epileptogenesis, and behavioral impairment. Eur J Neurosci 19: 3255 3265, 2004.

LEE CL, HRACHOVY RA, SMITH KL, FROST JD, Jr, SWANN JW: Tetanus toxin-induced seizures in infant rats and their effects on hippocampal excitability in adulthood. Brain Res 677: 97-109, 1995.

LEITE J, BABB TL, PRETORIUS JK, KUHLMAN PA, YEOMAN KM, MATHERN GW: Neuron loss, mossy fiber sprouting, and interictal spikes after intrahippocampal kainate in developing rats. Epilepsy Res 26: 219-233, 1996.

MAREŠ P, SEIDL J, NOVÁKOVÁ J: Different action of phenytoin and carbamazepine on cortical interhemispheric responses in young but not in adult rats. Neurosci Lett 160: 49-52, 1993 a.

MAREŠ P, SEIDL J, POHL M: Paired-pulse and frequency potentiation of cortical responses in developing rats. Brain Res Bull 32: 107-111, $1993 \mathrm{~b}$.

MAREŠ P, TSENOV G, ALEKSAKHINA K, DRUGA R, KUBOVÁ H: Changes of cortical interhemispheric responses after status epilepticus in immature rats. Epilepsia 46 (Suppl 5): 31-37, 2005.

OLNEY JW, COLLINS RC, SLOVITER RS: Excitotoxic mechanisms in epileptic brain damage. Adv Neurol 44: 857$877,1986$.

REJCHRTOVÁ J, KUBOVÁ H, DRUGA R, MAREŠ P, FOLBERGROVÁ J: Effects of a free radical scavenger Ntert-butyl-alpha-phenylnitrone $(\mathrm{PBN})$ on short-term recovery of immature rats after status epilepticus. Physiol Res 54: 215-227, 2005.

SANKAR R, SHIN DH, WASTERLAIN CG: Serum neuron-specific enolase is a marker for neuronal damage following status epilepticus in the rat. Epilepsy Res 28: 129-136, 1997.

SANKAR R, SHIN DH, LIU H, MAZARATI A, PEREIRA DE VACONCELOS A, WASTERLAIN CG: Patterns of status epilepticus-induced neuronal injury during development and long-term consequences. J Neurosci 18: 8382-8393, 1998. 
SANKAR R, SHIN D, MAZARATI A, LIU H, KATSUMORI H, LEZAMA R, WASTERLAIN CG: Epileptogenesis after status epilepticus reflects age- and model-dependent plasticity. Ann Neurol 48: 580-589, 2000.

SEGGIE J, BERRY M: Ontogeny of interhemispheric evoked potentials in the rat: Significance of myelination of the corpus callosum. Exp Neurol 35: 215-232, 1972.

SPERBER EF, HAAS KZ, STANTON PK, MOSHÉ SL: Resistance of the immature hippocampus to seizure-induced synaptic reorganization. Dev Brain Res 60: 88-93, 1991.

TURSKI WA, CAVALHEIRO EA, SCHWARZ M, CZUCZWAR SJ, KLEINROK Z, TURSKI L: Limbic seizures produced by pilocarpine in rats: behavioural, electroencephalographic and neuropathological study. Behav Brain Res 9: 315-336, 1983.

\section{Corresponding author}

P. Mareš, Institute of Physiology AS CR, Vídeňská 1083, 14220 Prague 4, Czech Republic. E-mail: maresp@biomed.cas.cz 